\title{
Lu-Hf изотопная систематика циркона и петрогенезис субщелочных и щелочных гранитов Кейвского мегаблока
}

\author{
Ветрин В.P. ${ }^{1,2}$, Белоусова Е.А. ${ }^{3}$, Кременецкий А.А. ${ }^{2}$ \\ ${ }^{1}$ Геологический институт КНЦ РАН, Anamumbl, vetrin@geoksc.apatity.ru \\ ${ }^{2}$ ФГБУ ИМГРЭ, Москва, nauka@imgre.ru \\ ${ }^{3}$ NSW 2109, Macquarie University, Dept. of Earth and Planetary Sciences, Faculty of Science, Sydney, \\ Australia,elena.belousova@mq.edu.au
}

\begin{abstract}
Аннотация. Изученные неоархейские щелочные и субщелочные граниты Кейвского мегаблока относятся к калиевым щелочно-известковым высокожелезистым породам, содержащим повышенные концентрации крупноионных, высокозарядных и редкоземельных элементов. Начальные отношения ${ }^{176} \mathrm{Hf} /{ }^{177} \mathrm{Hf}$ в центральных частях кристаллов циркона изменяются в пределах 0.281004-0.281175, и є $\mathrm{Hf}(\mathrm{T})$ - от -2.89 до 3.79 . Коэффициент фракционирования $\left.\mathrm{f}_{\mathrm{Lu}}=\left[\left({ }^{176} \mathrm{Lu} /{ }^{177} \mathrm{Hf}\right)_{\text {oбр }} \cdot{ }^{/ 176} \mathrm{Lu} /{ }^{177} \mathrm{Hf}\right)_{\text {сниR }}^{0}\right]-1$ во всех кристаллах имеет отрицательные значения и изменяется от -0.925 до -0.987 . Эти данные определяют формирование исходных расплавов за счет вещества коры, обедненного Lu и обогащенного Hf по сравнению с хондритом. При внедрении высокотемпературных базитовых расплавов в основание нижней коры происходило плавление метасоматически измененных нижнекоровых пород. При подъеме в верхнюю кору палингенные нижнекоровые расплавы изменяли свой состав в процессе фракционной кристаллизации с образованием более кремнекислых субщелочных и щелочных составов.
\end{abstract}

Ключевые слова: Субщелочные и щелочные граниты, неоархей, петрогенные и редкие элементы, циркон, Lu-Hf систематика, нижняя кора, петрогенезис, Кольский полуостров

\section{Lu-Hf isotope systematics of zircon and petrogenesis of subalkaline and alkaline granites of the Keivy megablok}

\author{
Vetrin V.R. ${ }^{1,2}$, Belousova E.A. ${ }^{3}$, Kremenetskiy A.A. ${ }^{2}$ \\ ${ }^{1}$ Geological Institute, Kola Sci. Centre of RAS, Apatity \\ ${ }^{2}$ Institute of mineralogy, geochemistry of rare elements, Moscow \\ ${ }^{3}$ Dept. of Earth and Planetary Sciences, Macquarie University, Sidney, Australia
}

\begin{abstract}
The studied Neoarchaean alkaline and sub-alkaline granites of the Keivy megablock refer to potassic alkali-calcic high-ferruginous rocks with high concentrations of LILE, HFSE and REE. Initial ratios of ${ }^{176} \mathrm{Hf} /{ }^{177} \mathrm{Hf}$ in central parts of the zircon crystals change in the range of $0.281004-0.281175$, and $\varepsilon \mathrm{Hf}(\mathrm{T})$ varies from -2.89 to 3.79 . The fractioning coefficient $\mathrm{fLu}=\left[(176 \mathrm{Lu} / 177 \mathrm{Hf})\right.$ sample/176Lu/177Hf $\left.{ }^{0} \mathrm{CHUR}\right]-1$ has negative values in all crystals and varies from -0.925 to -0.987 . These data define the formation of initial melts using the crustal matter poor in Lu and rich in Hf, compared to chondrite. When high-temperature basic melts intruded in the basement of the lower crust, there was melting of metasomatically altered rocks of the bottom crust. Polygenic melts of the bottom crust lifted to the upper crust, and changed their composition during the fraction crystallization and became more silicic sub-alkaline and alkaline.

Key words: subalkaline and alkaline granites, Neoarchaean, petrogenic and rare elements, zircon, Lu-Hf systematics, lower crust, petrogenesis, Kola Peninsula
\end{abstract}

При исследовании Кейвского мегаблока было показано несоответствие палеопротерозойских датировок щелочных пород, определяемых при изучении ряда изотопных систем (K-Ar, $\mathrm{Sm}-\mathrm{Nd}, \mathrm{U}-\mathrm{Pb}$ ) архейскому возрасту пород и минералов. Причиной этого несоответствия предполагается температурное и флюидное воздействие протерозойского магматизма и метаморфизма, обусловивших переустановку изотопных систем. Эффективным геохимическим критерием природы расплавов корового, мантийного или мантийно-корового генезиса, менее подверженным влиянию температурного фактора, является изотопный состав Hf в цирконе. Циркон устойчив к механическим воздействиям, слабо взаимодействует с расплавами и флюидами, имеет высокую температуру закрытия U-Th-Pb и Lu-Hf изотопных систем, вследствие чего является перспективным геохронометром и маркером петрологических процессов. Исходя из этого, нами выполнено изучение Lu-Hf 
изотопного состава циркона из неоархейских субщелочных гранитов Кукшинского массива (КМ), щелочных гранитов массивов Белые Тундры (БТ) и Понойского (ПМ), расположенных в южной и юго-западной частях Кейвского мегаблока.

Кремнекислые породы повышенной щелочности представлены ассоциацией латитовмонцонитов-гранитов (АЛМГ), комплексами субщелочных и щелочных гранитов. Геологопетрографическая и изотопно-геохимическая характеристика АЛМГ выполнена ранее (Ветрин, Родионов, 2009; Ветрин, 2018). Субщелочные и щелочные граниты содержат повышенные концентрации $\mathrm{K}, \mathrm{Rb}, \mathrm{Cs}$, Th, U, Zr, Hf, Р3Э, что в сочетании с низкими концентрациями Ba, Sr, P, Тi определяет резкие минимумы последних на мультиэлементных спектрах и характеризует существенно коровый источник расплавов. На диаграммах соотношения концентраций $\mathrm{SiO}_{2}$ и породообразующих окислов точки составов гранитов всех массивов образуют единые тренды с уменьшением содержаний $\mathrm{TiO}_{2}, \mathrm{Al}_{2} \mathrm{O}_{3}, \mathrm{FeO}^{*}, \mathrm{MgO}, \mathrm{CaO}$ и увеличением концентраций щелочей по мере роста $\mathrm{SiO}_{2}$. Наблюдаемые тренды изменения главных и второстепенных элементов в гранитах обусловлены, вероятно, различной степенью кристаллизационной дифференциации исходных средне- кремнекислых расплавов известково-щелочного и субщелочного составов.

\section{Lu-Hf изотопная система}

Кристаллы циркона из рассматриваемых пород имеют возраст 2.65-2.7 млрд. лет, включены в зерна плагиоклаза, имеют среднепризматический габитус с h:1 от 1:2 до 1:3 и характеризуется осцилляционной зональностью, что наряду с повышенным отношением $\mathrm{Th} / \mathrm{U}=0.45-50$ определяет их магматический генезис. Ядерные части кристаллов местами окружены темными в CL- излучении незональными оболочками с $\mathrm{Th} / \mathrm{U}=0.03-0.06$, образованными при метаморфизме пород в палеопротерозое.

Изотопный состав Hf в цирконе из датированных на SHRIMP II кристаллах определен в Университете Маквари, Сидней, Австралия методом лазерной абляции по методике (Griffin et al., 2000). Начальные отношения ${ }^{176} \mathrm{Hf} /{ }^{177} \mathrm{Hf}\left(\mathrm{Hf}_{\mathrm{i}}\right)$ центральных частей кристаллов находятся в пределах 0.281004-0.281175, и точки состава циркона образуют поле в районе тренда возрастной эволюции однородного хондритового резервуара (CHUR, рис. 1a). Преобладающая часть точек располагаются в полях составов циркона из плагиогнейсов Кольской сверхглубокой скважины, эклогитов южной части Кольского полуострова и находятся главным образом в поле составов АЛМГ и неоархейских кристаллов циркона из гранатовых гранулитов нижней коры. Согласно геохимическим и изотопно- геохимическим данным для всех изученных цирконов и вмещающих пород предполагается базитовый состав протолитов. По величине $\varepsilon \mathrm{Hf}(\mathrm{T})$ точки состава циркона находится в области развития коры с ${ }^{176} \mathrm{Lu} /{ }^{177} \mathrm{Hf}=0.015$ и возрастами в 3.1-3.2 млрд. лет (рис. 1б). Двухстадийный модельный возраст $\left(\mathrm{T}_{(\mathrm{DM})}{ }^{\mathrm{C}}\right)$ кристаллов циркона составляет 2.92-3.28 млрд. лет. Время нахождения протолитов в коре, определяемое разницей между модельным возрастом и временем кристаллизации циркона, оценивается в 260-620 млн. лет. Величина $\mathrm{Hf}_{\mathrm{i}}$ в метаморфогенных оболочках кристаллов циркона определена в 0.281234-0.281308, на 0.001-0.003 превышает величину $\mathrm{Hf}_{\mathrm{i}}$ в неоархейских ядрах кристаллов, и соответствует приращению этой величины в цирконе при развитии коры с возрастом 3.1-3.2 млрд. в условиях закрытой системы. На диаграмме в координатах «возраст, млн. лет - Нf точки состава оболочек расположены в полях составов циркона из лейкогранитов южной Финляндии и порфировидных гранитов сев. части Балтийского щита. Для последних образование исходных магм предполагается при плавлении базитовых пород нижней коры, испытавших процесс гранитизации в интервале 1.5-1.83 млн. лет. Коэффициент фракционирования $\left.\mathrm{f}_{\mathrm{Lu}}=\left[\left({ }^{176} \mathrm{Lu} /{ }^{177} \mathrm{Hf}\right)_{\text {обр. }}{ }^{176} \mathrm{Lu} /{ }^{177} \mathrm{Hf}\right)^{0}{ }_{\text {CHUR }}\right]-1$ во всех изученных цирконах имеет отрицательные значения и варьирует от -0.925 до -0.987. Средние значения коэффициента фракционирования в цирконе имеют близкие значения в субщелочных гранитах $\left(\mathrm{f}_{\mathrm{Lu}}=-0.974\right)$, щелочных гранитах БТ (-0.970) и ПМ (-0.968). Эти данные определяют формирование исходных расплавов всех массивов главным образом за счет сиалического вещества коры, обедненного Lu и обогащенного Hf по сравнению с хондритом. 

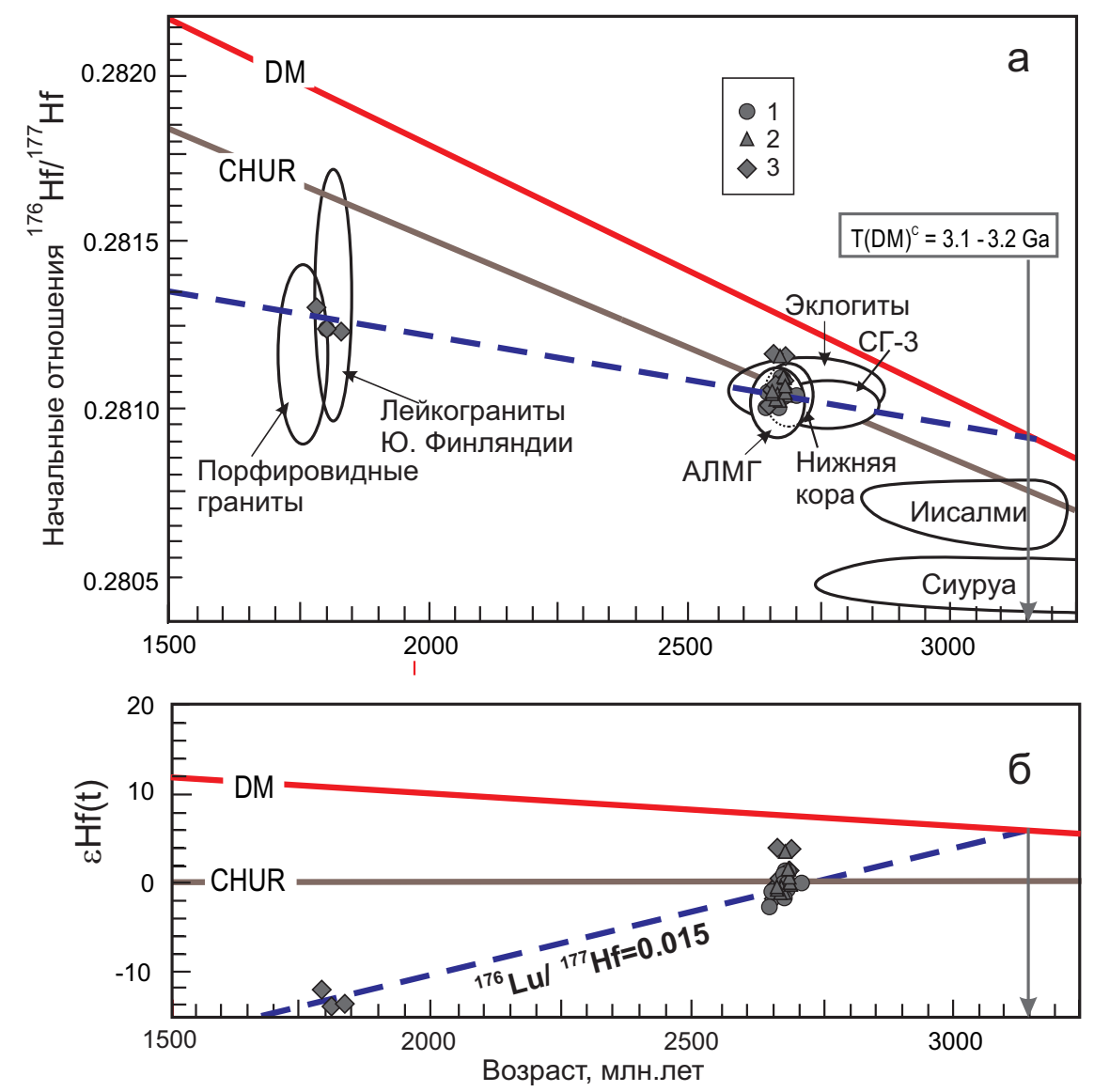

Рис. 1. Начальные изотопные отношения $\mathrm{Hf}_{\mathrm{i}}$ (a) и значения $\varepsilon \mathrm{Hf}(\mathrm{T})$ (б) в цирконе из гранитов.

Поля составов - по (Ветрин и др., 2016; Ветрин, 2018). Пунктиром показаны тренды эволюции коры с возрастами 3.1-3.2 млрд. лет при ${ }^{176} \mathrm{Lu} /{ }^{177} \mathrm{Hf}=0.015 .1$ - циркон из субщелочных гранитов; 2,3 - циркон из щелочных гранитов БТ и ПМ.

Fig. 1. Initial isotope relations of $\mathrm{Hf}_{\mathrm{i}}(\mathrm{a})$ and value $\varepsilon \mathrm{Hf}(\mathrm{T})(\mathrm{b})$ in zircon from granites.

Fields of composition - after (Vetrin et al., 2016; Vetrin, 2018). The dotted line indicates trends of evolution of zircon with age of 3.1-3.2 billion years at ${ }^{176} \mathrm{Lu} /{ }^{177} \mathrm{Hf}=0.015 .1$ - zircon from subalkaline granites; 2, 3 - zircon from the BT and PM alkaline granites.

\section{Обсуждение результатов}

Изученные граниты по составу относятся к калиевым, щелочно- известковым, высокожелезистым породам, содержащих повышенные концентрации крупноионных, высокозарядных и редкоземельных элементов. По величине отношения $\mathrm{Th} / \mathrm{U}=5.7$ граниты сопоставимы с породами нижней коры (6.0, Rudnick, Gao, 2003), что подтверждается и особенностями Lu-Hf изотопного состава циркона из рассматриваемых пород.

В настоящее время нет информации о составе пород нижней коры в пределах Кейвского мегаблока. Их наличие можно предполагать в составе диагностируемого по сейсмическим данным гранулит-базитового слоя на глубинах более 3-4 км (Литвиненко и др., 1968). В южной части Кольского полуострова отторженцы и ксенолиты нижней коры изучены в пределах Беломорского подвижного пояса, где представлены эклогитами (Mints et al., 2010; Скублов и др., 2011) и гранатовыми гранулитами (Kempton et al., 1995, 2001; Ветрин и др., 2017; Koreshkova et al., 2017). Протолиты эклогитов имеют состав оливиновых габбро, троктолитов, Fe-Ті габбро с возрастом $\geq 2820$ млн. лет (Mints et al., 2010). Протолиты гранатовых гранулитов по составу соответствуют главным образом палеопротерозойским метабазальтам - производным высокомагнезиальных бонинитоподобных расплавов, образующих в верхней коре Балтийского щита провинцию изверженных пород с возрастами 2.4-2.5 млрд. лет (Sharkov et al., 1999; Kempton et al., 2001). Исходя из этого к аналогам нижней 
коры Кейвского мегаблока могут быть отнесены, как представляется, мезоархейские породы основного состава, в настоящее время представленные эклогитами и жильными телами плагиогранитов с возрастами 2.87-2.78 млрд. лет (Mints et al., 2010). Поскольку процессы гранулитового и эклогитового метаморфизма в пределах Кейвского мегаблока не установлены, наиболее вероятным является амфиболит-плагиогранитный состав нижней коры. В отличие от Беломорского подвижного пояса, нижняя кора Кейвского мегаблока в неоархее была подвержена, вероятно, щелочному метасоматозу, обусловившему широкое развитие щелочных метасоматитов в породах верхней коры (Белолипецкий и др., 1980; Минц и др., 1996).

Изучение геологии и петрологии массивов щелочных гранитов Кольского полуострова свидетельствует о тесной возрастной и пространственной сопряженности основного и щелочного магматизма (Батиева, 1976). Щелочные граниты Понойского массива содержат ксенолиты основных пород - габбродиабазов, габбро, габброноритов, которые по составу и возрасту коррелируются с породами дайкового комплекса в окружении массива. Можно полагать, что основные магмы обеспечивали тепловой энергией и вносили свой вещественный вклад в частичное плавление нижней коры с образованием средних и кремнекислых расплавов, представлявших собой смесь производных плавления базитового и фельзического материала. Помимо этих составляющих кремнекислые расплавы могли, вероятно, содержать верхнекоровый и мантийный компоненты, обусловленные как процессами контаминации расплавов верхнекоровыми породами, так и влиянием глубинных магм.

Выдержанный по главным и редким элементам состав гранитов, а также отсутствие в них ксеногенных кристаллов циркона свидетельствует об ограниченном проявлении процессов контаминации расплавов материалом верхней коры. Это подтверждается и незначительными вариациями коэффициента фракционирования $\mathrm{f}_{\mathrm{Lu}}$ в гранитах всех массивов.

Мантийная составляющая в количестве 3-7 \% установлена в щелочных гранитах при изучении изотопного состава гелия, выделенного при отжиге первичных флюидных включений в акцессорном ильмените. Предполагается, что флюид, захваченный ильменитом при кристаллизации гранитов Понойского массива, был образован при смешении радиогенного гелия коры с ювенильным изотопом ${ }^{3} \mathrm{He}$ в соотношении (14-42): 1 (Ветрин и др., 2003).

Концентрации базитового и фельзического нижнекоровых компонентов в расплавах определялись по модели двухкомпонентного смешения. Вычисления производились по формуле $\mathrm{Xb}=\left(\varepsilon^{\mathrm{f}}-\varepsilon^{\mathrm{r}}\right) \mathrm{Hf}_{\mathrm{f}} /\left[\varepsilon^{\mathrm{r}}\left(\mathrm{Hf}_{\mathrm{b}}-\mathrm{Hf}_{\mathrm{f}}\right)-\left(\varepsilon^{\mathrm{b}} \mathrm{Hf}_{\mathrm{b}}-\varepsilon^{\mathrm{f}} \mathrm{Hf}_{\mathrm{f}}\right)\right] \mathrm{x} 100$, где $\mathrm{Xb}-$ концентрации базитового компонента, \%, $\varepsilon^{\mathrm{f}}, \varepsilon^{\mathrm{b}}, \varepsilon^{\mathrm{r}}-$ эпсилон $\mathrm{Hf}$ для фельзического, базитового и исследуемого образцов циркона, $\mathrm{Hf}_{\mathrm{f}}, \mathrm{Hf}_{\mathrm{b}}-$ концентрации Hf в цирконе из пород фельзического и базитового составов. В качестве характеристики базитового компонента при расчетах принят изотопный состав циркона мезоархейских габбро - протолитов $\mathrm{Fe}-\mathrm{Ti}$ эклогитов южной части Кольского полуострова с $\varepsilon \mathrm{Hf}_{(2670)}=5.65$, и в качестве фельзического компонента- изотопный состав циркона из жильного плагиогранита в эклогитах с $\varepsilon \mathrm{Hf}_{(2670)}=-3.55$. Концентрации Нf в расплавах приняты, соответственно, как $0.61 \%$ и $1.28 \%$ в цирконе из базальтов и гранитоидов (Belousova et al., 2002). Из выполненных расчетов следует, что концентрации базитового компонента в изученных кристаллах циркона, и, соответственно, в исходных расплавах, варьируют от 14 до 89 \% при наибольшей частоте встречаемости от 30 до $70 \%$. Средние значения Хb увеличиваются от 50 \% в цирконе из субщелочных гранитов КМ до 52 \% и 60 \% в цирконе щелочных гранитов, соответственно, БТ и ПМ.

\section{Выводы}

Предполагается, что около 2.7 млрд. лет назад к основанию литосферной мантии Кейвского мегаблока всплыл астеносферный диапир (астенолит), обусловивший ее плавление с образованием базитовых расплавов, представленных в верхней коре породами дайковых серий и ксенолитами в гранитах. Во время подъема астенолита сопровождавший и опережавший его флюидный поток производил предшествующее плавлению метасоматическое изменение (щелочной метасоматоз) литосферной мантии и расположенных выше пород коры с обогащением их щелочами и элементами примесями. При внедрении высокотемпературных базитовых расплавов в основание нижней коры про- 
исходило плавление метасоматически измененных нижнекоровых пород. Циркон из субщелочных и щелочных гранитов по изотопному составу близок составу цирконов из архейских пород, имевших базитовый состав протолитов. Количество базитового компонента нижней коры в образованных расплавах по результатам Lu-Hf систематики циркона оценивается в пределах 30-70 \%. Различным вкладом базитового и фельзического компонентов в состав расплавов объясняется, вероятно, и изменчивость редкоэлементного состава и изотопных Нf- характеристик кристаллов циркона. Мантийная составляющая в количестве 3-7 \% установлена в щелочных гранитах при изучении изотопного состава гелия, выделенного при отжиге первичных флюидных включений в акцессорном ильмените (Ветрин и др., 2003). Кремнекислые расплавы, образованные при плавлении метасоматически измененных пород нижней коры, в значительной степени наследовали, вероятно, ее обогащенный микроэлементами состав, определявший специфику внутриплитных гранитов A-типа (Frost, Frost, 2011). При подъеме в верхнюю кору палингенные нижнекоровые расплавы изменяли свой состав в процессе фракционной кристаллизации с образованием более кремнекислых субщелочных и щелочных составов.

Исследования выполнены по теме НИР 0226-2019-0052 при частичной поддержке РФФИ (грант 16-05-00756а) и госконтракта № 13/17-1.

\section{Литература}

1. Батиева И.Д. Петрология щелочных гранитоидов Кольского полуострова. Л.: Наука. 1976. 224 с.

2. Белолипецкий А.П., Гаскельберг В.Г., Гаскельберг Л.А. и др. Геология и геохимия метаморфических коплексов раннего докембрия Кольского полуострова. Л.: Наука. 1980. 240 с.

3. Ветрин В.Р. Изотопно-геохимическая систематика (Sm-Nd, Lu-Hf) неоархейских субщелочных и щелочных пород Кейвской структуры (Кольский полуостров): возрастные и генетические соотношения. Записки РМО. 2018. Ч. CXLVII. № 4. С. 1-13.

4. Ветрин В.Р., Родионов Н.В. Геология и геохронология неоархейского анорогенного магматизма Кейвской структуры, Кольский полуостров. Петрология. 2009. Т. 17. № 6. С. 578-600.

5. Ветрин В.Р., Белоусова Е.А., Чупин В.П. Редкие элементы и Lu-Hf изотопная систематика циркона из плагиогнейсов Кольской сверхглубокой скважины: вещество палеоархейской коры в мезоархейских метавулканитах. Геохимия. 2016. №1. С. 105-125.

6. Ветрин В.Р., Белоусова Е.А., Кременецкий А.A. Lu-Hf изотопная систематика циркона из ксенолитов нижней коры Беломорского подвижного пояса. Записки РМО. 2017. Ч. CXLVI. № 3. С. 1-16.

7. Ветрин В.Р., Каменский И.Л., Икорский С.В., Ганнибал М.А. Ювенильный гелий в архейских эндербитах и щелочных гранитах Кольского полуострова. Геохимия. 2003. №7. С. 699-705.

8. Литвиненко И.В., Анкудинов С.А., Платоненкова Л.Н., Сипарова Ю.А. Глубинный разрез Кейвской синклинорной зоны. Геология и глубинное строение восточной части Балтийского щита. Л.: Наука. 1968, C. $104-110$.

9. Минц М.В., Глазнев В.Н., Конилов А.Н. и др. Ранний докембрий северо-востока Балтийского щита: палеогеодинамика, строение и эволюция континентальной коры. М.: Научный мир. 1996. 287 с.

10. Belousova E.A., Griffin W.L., O’Reilly S.Y., Fisher N.I. Igneous zircon: trace element composition as an indicator of source rock type. Contrib. Mineral. Petrol. 2002. V. 143. P. 602-622.

11. Frost C.D., Frost B.R. On ferroan (A-type) granitoids: their compositional variability and modes of origin. J. Petrol. 2011. V. 52. P. 39-53.

12. Griffin W.L., Pearson N.J., Belousova E. et al. The Hf isotope composition of cratonic mantle: LAM-MC-ICPMS analysis of zircon megacrysts in kimberlites. Geochim. Cosmochim. Acta. 2000. V. 64. P. 133-147.

13. Kempton P.D., Downes H., Sharkov E.V. et al. Petrology and geochemistry of xenoliths from the northern Baltic Shield: evidence of partial melting and metasomatism in the lower crust beneath an Archean terrane. Lithos. 1995. V. 36. P. 157-184.

14. Kempton P.D., Downes H., Neymark L.A. et al. Garnet granulite xenoliths from the Northern Baltic Shield - the underplated lower crust of a Palaeoproterozoic large igneous province? J. Petrology. 2001. V. 42 . № 4. P. 731-763.

15. Koreshkova M., Downes H.,Millar et al. Geochronology of metamorphic events in the lower crust beneath NW Russia: a xenolith Hf isotope study. J. Petrol. 2017. V. 58. № 8. P. 1567-1590.

16. Mints M.V., Belousova E.A., Konilov A.N. et al. Mesoarchean subduction processes: 2.87 Ga eclogites from the Kola Peninsula, Russia. Geology. V. 38. № 8. P. 739-742.

17. Rudnick R.L., Gao S. Composition of the continental crust. In: Treasure on Geochemistry. Oxford: ElsevierPergamon. 2003. V. 3. P. 1-64.

18. Sharkov E.V., Snyder G.A., Taylor I.A., Zinger T.F. An Early Proterozoic large igneous province in the eastern Baltic Shield: evidence from the mafic drusite complex, Belomorian Mobile Belt, Russia. Geol. Review. 1999. V. 41. P. 73-93. 